\title{
Integrated Social-sector Macroeconometric Model for Pakistan
}

\author{
Hafiz A. Pasha, M. Aynul Hasan, Aisha Ghaus and M. Ajaz Rasheed
}

\section{INTRODUCTION}

While the traditional neoclassical production model postulates that it is the physical inputs such as private capital, labour, land, and technology that are the key determinants of output and economic development, in recent years, however, the social sector variables are also considered to be critical, particularly for the long-run sustainable growth of the economy. If fact, what has been argued in the form of "new growth theories" is that social variables (e.g., education, health, knowledge, etc.) generate "positive externalities" and, thus, may facilitate and foster the process of economic growth and development.

Recently, the World Bank, based on a broad cross-country study, found some very interesting results in the above context. According to the World Development Report (1991): about fifty percent of the factor productivity contribution to output growth comes not from traditional physical inputs (capital, labour and land) but is a residual factor. This unexplained factor, in the past, has been labelled (or as the Report called it "baptised”) as “technological change”, however, the World Bank (1991, p. 42) claims that:

Technological innovations have no doubt generated some improvement in total factor productivity. But the main additional element is in the quality of labour.

Of course, the quality of labour will come about due to education, skills, and the status of health that the society provides for the workforce.

Pakistan has traditionally given a relatively low priority to the social sectors as reflected in poor human development indicators of the country. However, Pakistan has

Hafiz A. Pasha is Deputy Chairman of the Planning Commission, Government of Pakistan, Islamabad. M. Aynul Hasan is at the Department of Economics, Acadia University, Canada. Aisha Ghaus is at the Social Policy and Development Centre, Karachi. M. Ajaz Rasheed is at the Social Policy and Development Centre, Karachi.

Authors' Note: The authors wish to thank Peter Pauly and Ashfaque Khan for valuable comments on an earlier version of the paper. Excellent research support was provided by Nadeem Ahmed and Nazia Bano. This study is funded by the Canadian International Development Agency (CIDA) and the authors wish to thanks the agency for providing financial support. Errors are sole responsibility of the authors. 
recorded a respectable economic growth rate of 6 percent per annum during the decade of the eighties. Apparently, low levels of literacy and poor health standards have not acted as a constraint to growth in the past. In fact, the view has sometimes been put forth that because Pakistan placed higher priority on public investment in economic and physical infrastructure as opposed to lager development outlays in the social sectors (see Table 1), it was able to accelerate its growth rate. Lately, it has been argued that while this was a successful development strategy in the short run, it was bound to fail eventually because of lack of human capital to sustain the process of future economic growth, especially in a changed international environment with greater competition for export among developing countries.

Undoubtedly, it is essential to develop a deeper understanding of the operation of the economy of a developing country like Pakistan and to analyse, in a long-term macroeconomic setting, the consequences of public investments in different sectors. In this context, in recent years, Pakistan has launched a major initiative with international donor agency support called the Social Action Programme (SAP). The SAP represents a big push forward of public expenditure in the social sectors with some diversion of resources from traditional areas of priority. In the aftermath of the launching of the SAP, concerns have been voiced by the provincial governments in Pakistan, who are primarily responsible for the delivery of basic social services such as education, health, water supply and sanitation, etc., about the financial sustainability of this programme. These governments have rapidly realised that, while accelerated development funding could potentially become available through SAP, there is no obvious source of revenue for financing the downstream operations and maintenance expenditures of the facilities created, especially since some of the social sectors like education and health are highly recurring expenditure intensive. The lack of recurrent funding could, therefore, adversely affect the fiscal position of provincial governments and require either larger inter-governmental revenue transfers or higher resource mobilisation. It is crucial to project the implications of this programme not only on the process of social development but also on the overall long-term rate of future economic growth, especially in a changed international environment with greater competition for export among developing countries.

The need has been felt in Pakistan for developing a macroeconomic model incorporating explicitly the impact of public expenditures (both social and economic), which are in excess of 30 percent of the GDP. Given the resource constraints being faced by all levels of government and the growing pressures to achieve greater macroeconomic stability by cutting down the national budget deficit, it has become necessary to evaluate the inter-sectoral priorities of public investment from the viewpoint of the maximum impact on the long-term growth potential of the country.

In view of the emerging social development issues and need for changing public expenditure priorities, this paper describes the integrated planning macroeconometric 
Table 1

Ranking of Countries in Indicators of Development of Social and Economic Infrastructure

\begin{tabular}{|c|c|c|c|c|c|c|c|c|c|c|c|c|c|c|c|}
\hline \multirow[b]{2}{*}{ Country } & \multicolumn{8}{|c|}{ Social Infrastructure } & \multicolumn{6}{|c|}{ Economic Infrastructure } & \multirow[b]{2}{*}{$\begin{array}{l}\text { Per Capita } \\
\text { Income } \\
\text { Ranking }\end{array}$} \\
\hline & $\begin{array}{c}\text { Primar } \\
\text { y } \\
\text { Enrol- } \\
\text { ment }\end{array}$ & $\begin{array}{l}\text { Secondary } \\
\text { Enrolment }\end{array}$ & $\begin{array}{l}\text { Hospital } \\
\text { Beds }\end{array}$ & Doctors & Nurses & $\begin{array}{l}\text { Drinking } \\
\text { Water }\end{array}$ & $\begin{array}{l}\text { Sani- } \\
\text { tation }\end{array}$ & $\begin{array}{l}\text { Overall } \\
\text { Ranking }\end{array}$ & $\begin{array}{l}\text { Electricity } \\
\text { Generation }\end{array}$ & Roads & $\begin{array}{l}\text { Tele- } \\
\text { phones }\end{array}$ & Railways & Irrigation & $\begin{array}{l}\text { Overall } \\
\text { Ranking }\end{array}$ & \\
\hline Nepal & 10 & 10 & 10 & 9 & 5 & 8 & 10 & 10 & 10 & 8 & 7 & 10 & 5 & 9 & 10 \\
\hline Bangladesh & 6 & 9 & 8 & 6 & 10 & 2 & 8 & 8 & 8 & 10 & 8 & 4 & 2 & 7 & 8 \\
\hline India & 5 & 4 & 4 & 2 & 6 & 4 & 7 & 3 & 2 & 1 & 5 & 2 & 3 & 1 & 6 \\
\hline Nigeria & 7 & 7 & 7 & 10 & 7 & 7 & 4 & 9 & 6 & 3 & 6 & 7 & 9 & 6 & 5 \\
\hline Pakistan & 9 & 6 & 5 & 3 & 9 & 6 & 5 & 6 & 3 & 5 & 2 & 3 & 1 & 2 & 4 \\
\hline Sri Lanka & 2 & 2 & 1 & 4 & 4 & 5 & 2 & 2 & 4 & 2 & 3 & 1 & 4 & 3 & 3 \\
\hline Egypt & 4 & 1 & 2 & 1 & 1 & 1 & 1 & 1 & 1 & 4 & 1 & 6 & 7 & 4 & 2 \\
\hline Indonesia & 1 & 3 & 6 & 5 & 8 & 9 & 3 & 4 & 5 & 7 & 4 & 8 & 6 & 5 & 1 \\
\hline Myanmar & 3 & 8 & 9 & 7 & 3 & 3 & 6 & 5 & 7 & 6 & 9 & 5 & 8 & 8 & 7 \\
\hline Sudan & 8 & 5 & 3 & 8 & 2 & 10 & 9 & 7 & 9 & 9 & 10 & 9 & 10 & 10 & 9 \\
\hline
\end{tabular}


model for Pakistan's economy that has been developed by the Social Policy and Development Centre (SPDC). The model clearly establishes linkages among the macroeconomy, public finances and the social sectors. It addresses a number of major policy issues including the relative impact of public investments (economic versus social infrastructure) on economic growth, the financial sustainability of the SAP, implications of privatisation of the public ventures and decentralisation of the process of delivery of services, etc.

Currently, the only major macroeconomic modelling initiative undertaken in Pakistan is by the Pakistan Institute of Development Economics (PIDE). The first attempt was made in 1979 and a completed document was produced in 1982. The model was relatively small initially with 53 equations. In the latest vintage of the model see Naqvi et al. (1993), the size has increased to 97 equations. The model now includes detailed modules for sectors related to production, expenditure, labour market, international trade, etc. However, the model does not have a developed public finance module and does not get into the issue of public expenditure allocations to different sectors, including the social sectors. A relatively small 33 equations model has also been developed by the AERC (1993). Although this model is rich on the public finance side, including fiscal linkages between federal and provincial governments, there is only a limited treatment of the macroeconomy.

The paper is organised as follows: Section 2 gives the overall structure of the model and delineates the linkages of various modules, blocks and equations. It also describes the special features of the model including mechanisms for financing of social sectors and endogenisation of factor productivity by development of a human capital index which enters explicitly into production functions of the economic sectors. Section 3 presents the findings of one of the important and interesting policy simulations. Finally, Section 4 gives the conclusions.

\section{STRUCTURE AND LINKAGES OF THE MODEL}

The model used in this study consists of 244 equations and covers several aspects of the economy. ${ }^{1}$ One of the unique features of the model is that, for the first time in Pakistan, it provides a planning tool wherein the social, public finance and macroeconomic dimensions of the economy have been integrated under one system. The model is dynamic, rich in specification and based on a pragmatic approach. Due to its highly disaggregated character, covering all three levels of government (federal, provincial and local), the model is capable of predicting variables in greater detail even at the level of provision of individual social services. It should be noted that such a disaggregation of the model at the provincial level, in terms of revenue and expenditures

${ }^{1}$ For a detailed discussion on the specification of the behavioural model, estimated regression equations, other statistical results, policy simulations etc., the reader may refer to Pasha et al. (1995). 
expenditures on social services (e.g., schools, hospitals, doctors, teachers, enrolment, etc.) is, in fact, necessary particularly in order to analyse the impact of SAP on the macroeconomy. The broad links of the model can be traced as follows (see Figure 1):

\section{Fig. 1. Basic Structure of the Model.}

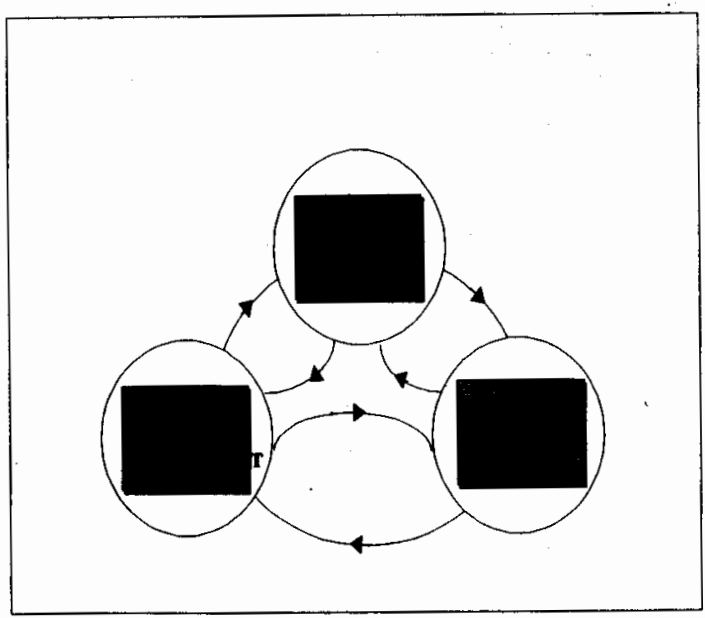

\section{Macroeconomy $\rightarrow$ Public Finance}

The key link here is that developments in the macroeconomy influence the growth of tax bases of taxes (including divisible pool taxes) and thereby affect the fiscal status of different governments. Also, the overall rate of inflation in the economy affects the growth of public expenditure.

\section{Public Finance $\rightarrow$ Social Sector Development}

The availability of resources, both external and internal, determines the level of development and recurring outlays to social sectors by different levels of government, especially the provincial and local governments.

\section{Social Sector Development $\rightarrow$ Macroeconomy}

Higher output of educated workers and their entry into the labour force raises the human capital stock and could contribute to improvements in productivity and higher growth rate of output in the economy. Similarly, an improvement in public health standards may also have a favourable impact on production.

\section{Public Finance $\rightarrow$ Macroeconomy}

The level of government expenditure could exert a demand side effect on national income while the size of the overall budget deficit of the federal and provincial 
governments combined influences the rate of monetary expansion and consequently the rate of inflation in the economy.

\section{Social Sector Development $\rightarrow$ Public Finance}

A vital link in the model is between the rate of social sector development and the state of public finances, especially of provincial governments, in terms of implications on the level of debt servicing and recurring expenditures.

\section{Macroeconomy $\rightarrow$ Social Sector Development}

Demographic and other socio-economic changes impact the demand for social sector facilities like schools, hospitals, etc., and thereby influence the level of social sector outputs.

\subsection{Intra-module Linkages}

Apart from these broad linkages among different modules, links exist between different blocks within each module too. In all, there are 39 major linkages in the model. Seven of these linkages are within the macro module, fifteen within the fiscal module and two within the social sector module. Major linkages within the macro module consist of, for example, the two-way linkage to and from the marco production block and macro input blocks. This link is due to the dependence of sectoral value-added on the factors of production and input demand functions on the value of production. Similarly, two-way linkages between the macro production and macro expenditure blocks arise due to the partial dependence of value-added in the services sectors on public expenditure and the causality between income and private consumption. Link between macro production block and trade block is due to the fact that value of imports and exports depend on the level of economic production activity.

Important linkages in the fiscal module consist of the simultaneous dependence of revenues of various levels of government and their expenditures. Non-tax receipts of governments have been made a function of the recurring expenditure on particular services via cost recovery ratios. Similarly, the level of government expenditure is affected by that government's level of resource generation. Important vertical links between levels of government include the fiscal transfers in the form of divisible pool transfers, non-development grants and ADP loans from federal to provincial governments and development grant requirements (in line with the feasible level of decentralisation) from provincial to local governments.

\subsection{Endogeneity and Factor Productivity of Public Investment}

One of the key features of this model is the inclusion of public sector investments in the form of social (human capital and public health indices) and economic infrastructure in the value-added production function. It has been argued that, along with 
private factor inputs (labour and capital), public sector investments may also contribute to the output of the economy. Unlike the private inputs which directly influence the production, the role of public investments is in the form of creating positive externalities and favourable environment (e.g., educated and healthy workers, roads, electricity, etc.). The model has the ability to estimate the direct and relative factor productivities of public social vis-à-vis economic infrastructure investments on the output of the economy.

The two types of public capital (social and economic) included in the model are endogenised under separate modules for human capital, public sector health and economic infrastructure. Within the human capital and public sector health modules, there exists a link between the level of social sector expenditures and the human capital and public health indices which, in turn, is expected to influence the productivity of the economy through the output production function. On the other hand, acting as a base for the public revenues, the output of the economy may also indirectly impact on the social variables through social sector expenditures.

\subsection{Financing of Public Social-sector Investments}

In Pakistan, the process of financing and execution of social services is quite complex with involvement of all three levels of governments (i.e., federal, provincial and local). While the principal responsibility of operation and maintenance (O\&M) of social services rests with the provincial (state) and local governments, the role of the federal government is limited to the provision of social services in federally administered areas. Consequently, over 80 percent of the total expenditure on social sectors is incurred by the provincial and local governments, the share of the former being about 65 percent.

The existence of structural imbalance between the functional responsibilities and fiscal powers at different levels of government has necessitated the establishment of elaborate inter-governmental revenue-sharing arrangements particularly between the federal and the four provincial governments in Pakistan. Provincial governments finance their expenditures from various tax and non-tax sources (constitutionally under their fiscal powers), federal revenue sharing transfers (which includes divisible pool and straight transfers), grants and development transfers (including donor funds) received from the federal government. In 1994-95, for example,15 percent of the provincial recurring expenditures was financed by own sources ( 8 percent taxes and 7 percent user charges), 75 percent from revenue sharing transfers, 11 percent from grants from federal government while almost all of the provincial development outlays were financed from federal development transfers, largely consisting of loans and donor funds. Clearly, the bulk of provincial income comes from the federal government and is outside the direct control of the provincial governments. As such, modelling of inter-governmental fiscal transfers is a crucial feature of the model. 
Unlike the provincial governments, local governments are largely self-financing entities in Pakistan. They mostly rely on own tax and non-tax revenues to finance their ongoing operation and maintenance costs and the development of new schemes. Almost 55 percent of the total (recurring and development) expenditure of local government is financed by own tax collection, 18 percent by user charges, 6 percent by revenue sharing transfers from the provincial governments and 8 percent by grants.

\section{POLICY SIMULATIONS}

In order to demonstrate the usefulness of the integrated planning model, as an example, we present results of an interesting policy simulation, namely, change in investment priorities from economic to social sector investments. In order to keep the discussion as simple and intuitive as possible, only the important linkages and impact of a policy initiative on the GDP will be presented with the help of a diagram.

\subsection{Change in Investment Priority}

We examine whether shifting funds from public economic infrastructure investment towards social sector development produces any positive impact on the macroeconomy, especially in the long run (up to 2002-03). A change in the priority of public investment from economic to social sectors will simply require a reallocation of resources within the existing total annual development programme (ADP) which includes total capital outlays of both the federal and provincial governments. Since the federal government is primarily responsible for providing economic infrastructure and since the bulk of the social investment is provided by the provincial governments, direct transfer of resources from the former to the latter governments must take place in such a way so that the total $A D P$ remains unchanged. After the implementation of this policy, less federal public funds will be available for new economic infrastructure investment and hence a direct negative impact on the Gross Domestic Product (GDP) is expected.

With more funds now diverted from federal $A D P$ to provincial governments, specifically earmarked for the social sectors, it will now enable the provincial governments to undertake an expanded development programme, particularly in the areas of education, health and other social sectors (sanitation, clean water, etc.). This type of programme, of course, is expected to have some immediate positive impact on the actual provision of social services and, subsequently, after a time lag, through the human capital and public health indices, it may also influence the GDP of the economy.

The critical interesting issue that needs to be examined, in this context, is whether the postulated positive and negative linkages of the above policy hold true and, if so, what is the duration of the lag. This is essentially an empirical issue and Figure 2 reports the results of such a policy on GDP. Clearly, the stipulated linkage is visible as shown by a dark $U$ shaped curve marked $B$ in Figure 2 . This curve simply represents changes in the GDP from the "baseline" due to the implementation of the policy. It is 
important to note that, as a result of changes in investment priority from the economic to the social sectors, initially, there is a deterioration in the GDP for about eight years (up to 2001) after which the changes in GDP become positive.

What is even more interesting and important to note is that, while the time lag required for $G D P$ to become positive is independent of the size of the policy changes, the long-run revival of the $G D P$, however, is not independent of the initial strength of the policy. In simple words, what this means is that if the government undertakes a less than enthusiastic policy of diverting resources from the economic to the social sector, a long-run positive gain will be made but in small proportions as shown by curve $W$. in Figure 2. On the other hand, if the government pursued a more aggressive policy (four times that of the baseline), in the short to medium run, there will be a sizeable deterioration initially in the $G D P$. However, during this period, such policies will result in improved human capital and public health endowment of the nation. Consequently, with the enriched social endowments (educated and healthy workers), once the society crosses the critical time path of about eight years, the upturn in the GDP will be significant and long lasting as shown by curve $A$ in Figure 2 .

Fig. 2. Shifting Investment Priorities

From Economic to Social Sectors

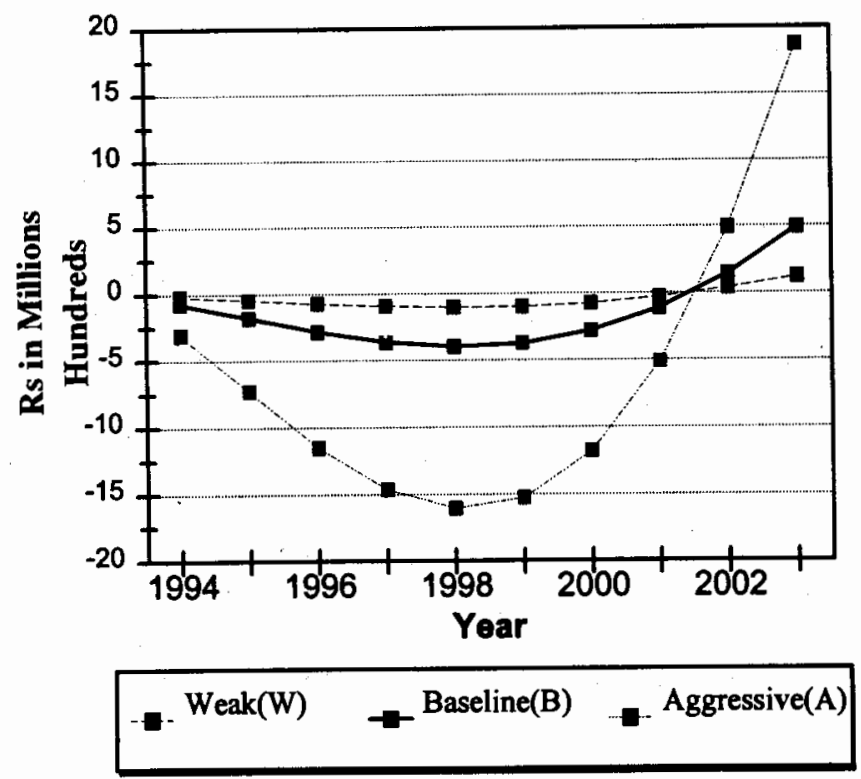

Intuitively, the implications of the above policy are as follows. Investment in the social sectors have a long gestation period, much longer than that of investments in 
economic sectors. No matter what amount of public investment is made, small or large, for the social sectors, the realisation of the returns unlike the economic investments (in the form of robots or machines), will take its own time. An aggressive policy, however, in this context, (as pursued by countries like Singapore, South Korea, Malaysia, Taiwan, and others in the region) may also take the same time but the impact of such concerted and well designed policies will be much greater and long lasting. In social sector investment, policy-makers ought to take a long-run, well-thought visionary approach as the money spent on this sector does not automatically guarantee future prosperity but without such investments in human capital, no nation, in recent period, has ever been able to achieve the status of even a middle income country.

\section{CONCLUDING REMARKS}

This study represents a first attempt at developing a relatively large (244 equations) planning macroeconometric model for Pakistan that integrates the social, public finance and macroeconomic dimensions of the economy. The model is dynamic, behaviourally rich in specification, based on a pragmatic approach and incorporates a large number of inter-module and inter-block linkages. Special features of the model include the detailed modelling of the process of financing of social sectors with special

emphasis on inter-governmental transfers and explicit incorporation of the impact of economic and social infrastructure on the productive sectors, with the latter being captured by changes in factor productivity measured by human capital and public health indices, especially developed as part of the model.

Despite the shortness of the time series and softness of some of the data, the application of a number of formal and informal econometric tests to check for goodnessof-fit, serial correlation, heteroskedasticity and specification reveal that the model performs fairly well. The use of a number of dummy variables is justified on the grounds of random shocks and structural shifts. The validation exercise also highlights the high ex post forecasting power of the model.

A number of important policy simulations of the model have been undertaken which lead to some key insights. For example, a change in public investment priority from economic towards social infrastructure depresses the GDP in the short run but pays dividends in terms of a higher national income after a lag of about eight years. Similarly, launching of accelerated development programmes in the social sectors like the SAP have significant GDP impacts but could exacerbat the problem of the national budget deficit. Altogether, the model has considerable flexibility and can be used to answer a number of important policy questions. 
Appendix

\section{Data Sources and Definition of Selected Variables}

The availability of official statistics in Pakistan is largely the result of efforts by the Federal and Provincial Bureaus of Statistics in consolidating information from line and staff departments and publishing these, to the extent possible, in the Pakistan Statistical Year Book at the Federal level and the provincial Development Statistics by each of the federating units. A closer examination of the statistics published by the primary agencies and the consolidated figures suggests that there are inconsistencies in the data which result in a number of statistics being suspect. In addition, data on macroeconomic, financial, money and fiscal variables are also published by the Ministry of Finance (the annual Budget, the Pakistan Economic Survey), the provincial Finance Departments (the annual Budgets) and the State Bank of Pakistan (the Annual Report). Where inconsistencies between primary agency data and consolidated data have been observed for some of the years, we have adopted a general rule that a value which is closer to the trend revealed by the consolidated data has been assumed to be more reflective of actual conditions.

\section{Public-sector Health Index}

Information on the health status of the population is best measured through morbidity rates and the incidence (or lack of it) of communicable diseases. In addition some studies have also used infant mortality, child-birth deaths, rates of immunisation and such other indicators as a means to studying the health status of a population. In the absence of such sophisticated data, an alternative had to be developed. We have attempted to do this through the Public Health Index (PHI) which suggests that the inputs into looking after the health of people or providing health care services are reflective of the health status of the population. We have constructed the PHI through a factor analysis technique. The technique draws upon the inter-relationship of a group of highly correlated variables to band them into one variable and the cross-relationship this group has with other homogenous vectors of variables. Each vector of variables (factors) are then considered to be one homogenous whole and the cross-relationships used to develop a factor scores (based on coefficients and eigen values) which explain the impact of each factor on the dependant variable.

The data used to construct the Public Health Index aggregates the provincial data on Basic Health Units (BHUs), Rural Health Centres (RHCs), Sub-Health Centres (SHCs), Mother and Child Health Centres (MCHs), TB centres, Doctors, and Nurses over the period 1971-72 to 1992-93. The factor scores for the country as a whole for

each year have then been used to develop the index with the initial year 1971-72 as the base. 


\section{Human Capital Index}

The Human Capital Index (HCI) is used to capture the quality aspect of labour based on their level of education and professional skills. Data for the development of this index by economic sectors, namely, agriculture, manufacturing and others, requires information on the labour force composition with respect to their skill and education. The data source is the annual Labour Force Survey undertaken by the provincial Labour Departments and compiled by the Federal Bureau of Statistics.

In addition to this, data on relative wages is needed for assigning weights to individual segments to capture the qualitative human attributes. This is based on the premise that in a free competitive market wage rates at the margin must be equal to the value of marginal productivity of a worker. Presumably, the productivity of labour is a direct reflection of worker education and skill levels.

Information on wages is obtained from the annual Household Income and Expenditure Surveys conducted by the Federal Bureau of Statistics. To offset the inflationary effect, the implicit GDP deflator has been used to estimate wages at the constant price of 1991-92. The data on GDP deflator has been compiled from the annual Pakistan Economic Survey published by the Ministry of Finance and Economic Affairs.

The HCI has been constructed using the wage rate and number of employed persons. The labour force and wage rate are divided into eight separate categories with respect to professional skill, namely:

(a) professional and technical;

(b) administrative and managerial;

(c) clerical;

(d) sales worker;

(e) service worker;

(f) agricultural worker;

(g) production worker; and

(h) other occupation.

The formula for constructing the human capital index for the ' $K$ th' sector at period ' $t$ ' can be written as:

$$
H C I_{k t}=\frac{\left(\sum_{i}^{8} L_{k, i, t}\left(W_{k i} / W_{k, a g}\right)\right)}{L_{k}}
$$

Where

$$
\begin{aligned}
i & =\text { professional occupation; } \\
t & =\text { time (I to } \mathrm{n}) ; \text { and } \\
k & =\text { sectors. }
\end{aligned}
$$




\section{REFERENCES}

AERC (1993) A Model of Public Finance in Pakistan. Karachi: Applied Economic Research Centre, University of Karachi.

Naqvi, S. N. H., A. Khan and A. Ahmed (1993) The Macro-economic Framework for the Eighth Five-year Plan. Islamabad: Pakistan Institute of Development Economics.

Pasha, H., M. A. Hasan, A. Ghaus and A. Rasheed (1995) Integrated Social Policy and Macroeconomic Planning Model for Pakistan. Karachi: SPDC Publications,

World Bank (1991) World Development Report 1991. New York: Oxford University Press. 